\title{
Motion Preserving Techniques for Treating Cervical Radiculopathy
}

\section{Gun Choi ${ }^{1 *}$ and Alfonso García ${ }^{2}$}

${ }^{1}$ Neurosurgeon, President of Wooridul Spine Hospital, Pohang, South Korea

${ }^{2}$ Orthopedic Surgeon, Spine Surgery Fellow at Wooridul Spine Hospital, Pohang, South Korea

\section{Mini Review}

Up to date the seasoned spine surgeon has many options for the treatment of Cervical Radiculopathy that range from muscle and motion preserving procedures to the well-known Anterior Cervical Discectomy and Fusion and the Anterior Cervical Disk Replacement surgeries. We wish to present a brief review of the literature to address two minimally invasive and motion preserving techniques known as, Cervical Transcorporeal Tunnel Approach and Percutaneous Endoscopic Cervical Discectomy, respectively.

\section{Cervical Transcorporeal Tunnel Approach}

The surgical management of cervical radiculopathy has evolved considerably over the past decades; however, no surgical treatment is without associated morbidity or limitations. Traditional techniques of treating patients with radiculopathy from cervical spondylosis have relied on posterior, anterior, and now oblique-based approaches. Minimally invasive approaches and surgical techniques are becoming increasingly popular for the treatment of a variety of cervical spine disorders [1]. Thanks to the development of high quality endoscopes and video imaging, we have been able to reach the entire spinal column from the Cervical to Lumbosacral segments, with the primary goal to achieve outcomes comparable to those of open surgery but with less bleeding, while minimizing healthy tissue damage, reducing recovery times and hospital stay. The history of anterior microforaminotomy for cervical radiculopathy can be dated back to 1968 [2-4] where attempts were made to achieve decompression by partial removal of the offending disc material. The pioneering disc sparing approach was reported by Jho [5] in 1996, but this technique required the exposure of vertebral artery along its medial surface. This approach was later modified by Saringer [6] in 2000 who recommended preserving a thin piece of lateral wall of the uncinate process, avoiding exposure of the vertebral artery but involving transverse resection of longus coli muscle therefore increasing the risk of injury to cervical sympathetic chain and Horner's syndrome. We have modified the technique of upper vertebral transcorporeal anterior foraminotomy for the treatment of cervical radiculopathy by avoiding breaching the medial wall

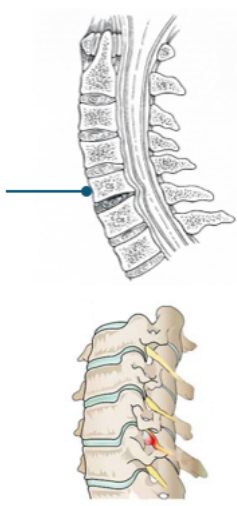

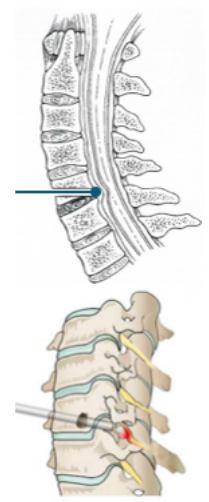

B
Figure 1: Transcorporeal foraminotomy is done through an open Smith \& Robinson anterior approach. (A) Shows the starting point for drilling and (B) demonstrates the complete decompression of foraminal area, with preservation of disc space.

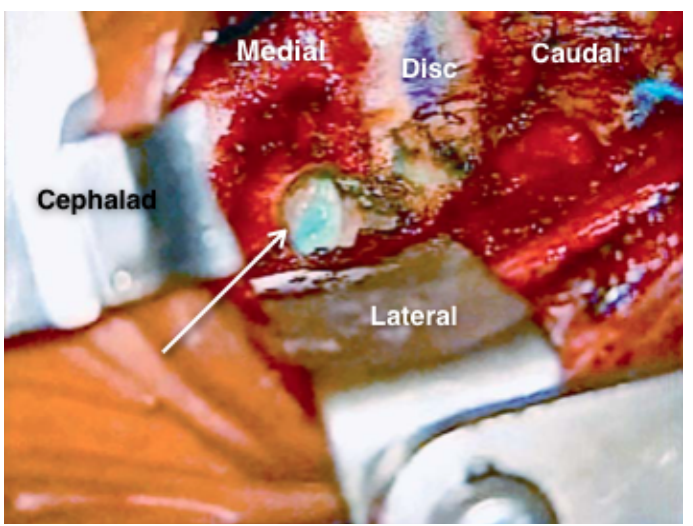

Figure 2: Microscopic view, showing transcorporeal drill hole (arrow), with blue stained disc at the bottom. The oblique blue stain appearance of the disc is because we are at the level of the uncovertebral joint space.

of transverse foramen and attempting to preserve the lower end plate $[7,8]$ (Figures 1 and 2).

The main goals for this technique are:

- Direct anterior decompression.

- Preservation of disc height.

- Avoidance of complications related to anterior fusion surgery.

- Avoidance of exposure and injury to vertebral artery and cervical sympathetic chain.

Advantages are related with: a direct approach to pathology, motion preservation, faster recovery and no need for postoperative immobilization.

\section{Indications include:}

- Unilateral and acute cervical radiculopathy not responding to conservative treatment.

- Upper limb motor weakness secondary to herniated disc or foraminal stenosis.

- Imaging studies corresponding to clinical features.

Contraindications are as follows:

- Patients with dominant axial neck pain.

- Cervical instability.

*Corresponding author: Gun Choi, Neurosurgeon, President of Wooridul Spine Hospital, Pohang, South Korea, Tel: 82-54-240-6000; E-mail: spine.choi@gmail.com

Received August 12, 2015; Accepted August 20, 2015; Published August 22, 2015

Citation: Choi G, García A (2015) Motion Preserving Techniques for Treating Cervical Radiculopathy. J Spine 4: 247.doi:10.4172/21657939.1000247

Copyright: ( 2015 Choi G, et al. This is an open-access article distributed under the terms of the Creative Commons Attribution License, which permits unrestricted use, distribution, and reproduction in any medium, provided the original author and source are credited. 
- Cervical infection, or tumor.

Relative contraindications are:

- Patients with bilateral cervical radiculopathy.

- Patients with previous ACDF surgery at/or one level above the affected level.

- Patients with cervical stenosis.

- High cervical levels (C3-4 \& above).

Current studies that report clinical outcomes after cervical transcorporeal anterior foraminotomy include patient subjects that range from 40 to 100, with a mean postoperative followup of 27 months ranging from 12 to 36 months. Early results are promising, with excellent outcomes that range from $67 \%$ to $92 \%$. Revision rate varies from $1 \%$ to $6.4 \%$. The clinical impact of preserving the native anatomical architecture during Transcorporeal Microdiscectomy procedures should be investigated in future dedicated studies of long term functional and radiographic outcomes [7-10].

\section{Percutaneous Endoscopic Cervical Discectomy}

The development and propagation of the anterior cervical approach, initially by Smith and Robinson [11], and later by Cloward [12] led to the formation of the today's era anterior cervical discectomy with or without fusion for patients suffering from cervical radiculopathy. Their principle was based on the simple idea of direct anterior decompression of the offending structure but was associated with either loss of disc height (in patients without fusion) or loss of a mobile segment (in patients with interbody fusion). Furthermore patients undergoing anterior decompression and fusion in the long run developed fusion related complications namely, adjacent segment disease, pseudoarthrosis and other graft related problems [13]. Indirect decompression using minimally invasive posterior lamino-foraminotomy fails to address the pathology anterior to the root i.e. foraminal osteophytes, ruptured disc. Percutaneous endoscopic cervical discectomy (PECD) with assisted laser has been reported as a minimally invasive procedure for soft disc herniation and cervicogenic headache associated with lower cervical spine segments (C3-C7) [14-16].

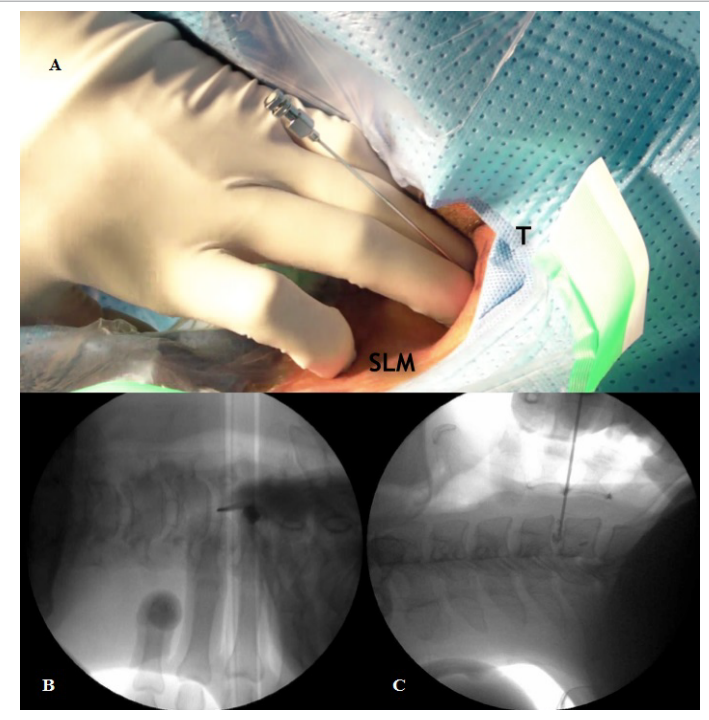

Figure 3: Right side approach, surgeon uses third and fourth digits to create a space between trachea (T) and sternocleidomastoid muscle (SCM). He then places a needle and after verifying correct level $(B, C)$ with $C$ arm fluoroscopy, a discogram is made.

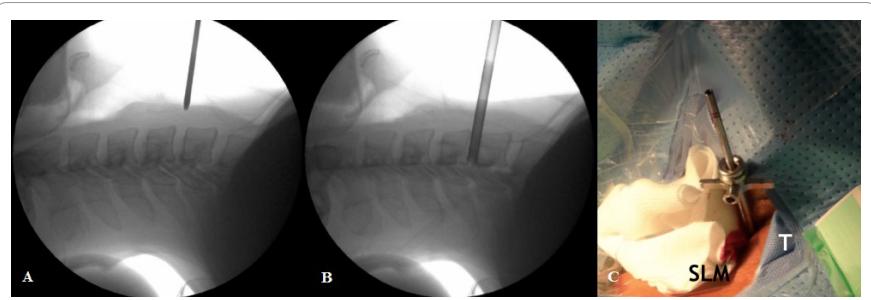

Figure 4: A small skin incision $(6 \mathrm{~mm})$ is made, and sequential dilators are introduced over guide wire $(A)$. Finally working cannula is placed in position $(B, C)$.

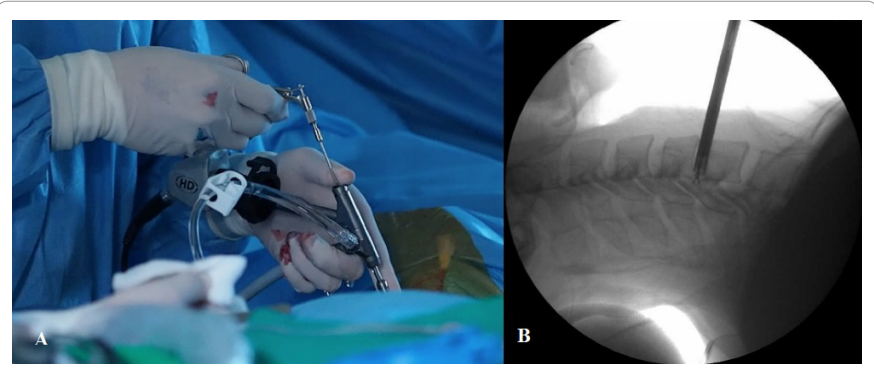

Figure 5: (A) A $3.9 \mathrm{~mm}$ working channel scope is passed through the $5 \mathrm{~mm}$ cannula and visual removal of herniated disc can be accomplished with the aid of $\mathrm{C}$ arm fluoroscopy (B).

PECD has been proven to be successful as reported by several authors [17-20]. From long-term outcomes by Lee JH and Lee SH, where it was clearly stated that the reduction of disc height and progression of disc degeneration did not have any effect on clinical symptoms [21], and later in 2014 by Kim CH and Shin KH, finding that cervical curvature does not worsen after posterior PECD [22]. All of these studies have provided the needed results to prove that PECD can be an excellent option for treating also various cervical disc problems under meticulous patient selection.

Although PECD was was mainly indicated for soft disc herniations compressing the dura or nerve root without definite segmental instability. The percutaneous anterior approach is not suitable for the C2-3 intervertebral disc, since it carries the risk of pharyngeal injury. Therefore, this procedure was indicated for discs below the C3 level [14].

The effect of endoscopic manual and laser discectomy in pain relief may be explained by the following mechanisms: first, the denaturation of annular neovascularization and neoneuralization [23,24]; second, the direct ablation of the hernia mass; third, a decrease in intradiscal pressure; and last, shrinkage of the nucleus pulposus.

The advantages of PECD is that besides being a minimally disruptive procedure, it needs to be done with patient fully awake and local anesthesia, this provides the much needed safety net to monitor patient's condition while decompressing neural structures (Figure 3).

Other advantage is that it has effects of both decompressive surgery and thermal neurotomy/denaturation of radio frequency (RF). In discogenic cervical headaches, the pain triggering structures (except the facet joint capsule) are the nerve root, disc, longitudinal ligament and dura. This decompressive thermodiscoplasty effect can cover all these structures with minimal change to normal anatomy (Figures 4 and 5).

\section{Indications include:}

- Low cervical (C3 to C7) soft disc herniations without segmental instability

- Cervicogenic headache. 
PECD is not recommended in the following cases:

- Patients with previous anterior cervical surgery.

- Patients with dominant axial neck pain.

- Cervical instability.

- Cervical infection, or tumor.

- High Cervical level pathology (C3-C4 and above)

Relative contraindications are:

- Patients with bilateral cervical radiculopathy.

- Patients with calcified disc and/or foraminal stenosis.

- Patients with cervical stenosis not related to soft disc herniation

Even though we have some studies that provide information on the safety and good results from this procedure, they are still preliminary and with relative limitations due to small number of cases reported and followup. In order to provide further evidence, we need to continue to share common knowledge and clinical experience to create awareness and refine the characteristics of the ideal patients who can benefit from this very promising technique. I am convinced that, as surgeons skills, knowledge and perspectives advance with technology, endoscopic and other motion and muscle preserving techniques will be the gold standard for the treatment of common spine problems on an outpatient setting.

\section{References}

1. Celestre PC, Pazmiño PR, Mikhael MM, Wolf CF, Feldman LA, et al. (2012) Minimally invasive approaches to the cervical spine. Orthop Clin North Am 43: 137-147.

2. Verbiest $H$ (1968) A lateral approach to the cervical spine: technique and indications. J Neurosurg 28: 191-203.

3. Hakuba A (1976) Trans-unco-discal approach. A combined anterior and lateral approach to cervical discs. J Neurosurg 45: 284-291.

4. Lesoin F, Biondi A, Jomin M (1987) Foraminal cervical herniated disc treated by anterior discoforaminotomy. Neurosurgery 21: 334-338.

5. Jho HD, Kim WK, Kim MH (2002) Anterior microforaminotomy for treatment of cervical radiculopathy: part 1--disc-preserving "functional cervical disc surgery". Neurosurgery 51: S46-53.

6. Saringer W, Nöbauer I, Reddy M, Tschabitscher M, Horaczek A (2002) Microsurgical anterior cervical foraminotomy (uncoforaminotomy) for unilatera radiculopathy: clinical results of a new technique. Acta Neurochir (Wien) 144 685-694.

7. Choi G, Lee SH, Bhanot A, Chae YS, Jung B, et al. (2007) Modified transcorporeal anterior cervical microforaminotomy for cervical radiculopathy: a technical note and early results. Eur Spine J 16: 1387-1393.
8. Choi G, Arbatti NJ, Modi HN, Prada N, Kim JS, et al (2010) Transcorporea tunnel approach for unilateral cervical radiculopathy: a 2-year follow-up review and results. Minim Invasive Neurosurg 53: 127-131.

9. Lowry DW, Tuinstra SM, Liang K, Sclafani JA (2015) Clinical Outcomes After Cervical Transcorporeal Microdecompression and Vertebral Body Access Channel Repair. International Journal of Spine Surgery 9: 1-6.

10. Pechlivanis I, Brenke C, Scholz M, Engelhardt M, Harders A, et al. (2008) Treatment of degenerative cervical disc disease with uncoforaminotomyintermediate clinical outcome. Minim Invasive Neurosurg 51: 211-217.

11. Smith GW, Robinson RA (1958) The treatment of certain cervical-spine disorders by anterior removal of the intervertebral disc and interbody fusion. $J$ Bone Joint Surg Am 40-40A: 607-24.

12. Cloward RB (1958) The anterior approach for removal of ruptured cervical disks. J Neurosurg 15: 602-617.

13. Lopez-Espina CG, Amirouche F, Havalad V (2006) Multilevel cervical fusion and its effect on disc degeneration and osteophyte formation. Spine (Phila Pa 1976) 31: 972-978.

14. Ahn Y, Lee SH, Chung SE, Park HS, Shin SW (2005) Percutaneous endoscopic cervical discectomy for discogenic cervical headache due to soft disc herniation. Neuroradiology 47: 924-930.

15. Ahn Y, Lee SH, Lee SC, Shin SW, Chung SE (2004) Factors predicting excellen outcome of percutaneous cervical discectomy: analysis of 111 consecutive cases. Neuroradiology 46: 378-384.

16. Knight MT, Goswami A, Patko JT (2001) Cervical percutaneous laser disc decompression: preliminary results of an ongoing prospective outcome study. J Clin Laser Med Surg 19: 3-8.

17. Choi G, Lee SH (2008) Textbook of spine. Korean Spinal Neurosurgery Society $1173-1185$

18. Lee SH, Lee JH, Choi WC, Jung B, Mehta R (2007) Anterior minimally invasive approaches for the cervical spine. Orthop Clin North Am 38: 327-337.

19. Ruetten S, Komp M, Merk H, Godolias G (2008) Full-endoscopic cervical posterior foraminotomy for the operation of lateral disc herniations using 5.9 $\mathrm{mm}$ endoscopes: a prospective, randomized, controlled study. Spine (Phila $\mathrm{Pa}$ 1976) 33: 940-948.

20. Ahn Y, Lee SH, Shin SW (2005) Percutaneous endoscopic cervical discectomy: clinical outcome and radiographic changes. Photomed Laser Surg 23: 362-368.

21. Lee JH, Lee SH (2014) Clinical and radiographic changes after percutaneous endoscopic cervical discectomy: a long-term follow-up. Photomed Laser Surg 32: 663-668.

22. Kim CH, Shin KH, Chung CK, Park SB, Kim JH (2015) Changes in cervical sagittal alignment after single-level posterior percutaneous endoscopic cervical discectomy. Global Spine J 5: 31-38

23. Knight MT, Goswami A, Patko JT (2001) Cervical percutaneous laser disc decompression: preliminary results of an ongoing prospective outcome study. $J$ Clin Laser Med Surg 19: 3-8.

24. Freemont AJ, Peacock TE, Goupille P, Hoyland JA, O'Brien J, et al. (1997) Nerve ingrowth into diseased intervertebral disc in chronic back pain. Lancet 350: $178-181$ 